\title{
Inferences About the Authentic Self: When Do Actions Say More Than Mental States?
}

\author{
Joel T. Johnson \\ University of California, Davis
}

\author{
Michael D. Robinson \\ North Dakota State University
}

\author{
Emilie B. Mitchell \\ University of California, Davis
}

\begin{abstract}
Three studies involving 478 undergraduates examined the perceived importance of observable actions versus mental states in revealing the "true self" - the authentic and fundamental nature of a target person. Results suggest that when people have only limited information about a target, they believe that an action is more diagnostic of the individual's true self than the accompanying mental state. When participants have knowledge concerning chronic dispositional tendencies of the target, however, they judge that a chronic mental state is more diagnostic of the true self than a chronic action tendency. Considered together, the findings suggest that people conceptualize the true self as a relatively private entity but nevertheless believe that an action of a little-known person may be particularly informative about that individual. Perceived diagnosticity of the true self was partially mediated by inferences concerning the relative stability of actions versus states but not by inferences of volition.
\end{abstract}

As a man thinketh in his heart, so is he.

Truth is communicated to men only by deeds of truth -Leo Tolstoy

Well, one might say this: If one sees the behavior of a living thing, one sees its soul.

—Ludwig Wittgenstein, Philosophical Investigations

People come in four types: The pomegranate (hard on the outside, hard on the inside), the walnut (hard-soft), the prune (soft-hard), and the grape (soft-soft).

—Muhammad Ali

The final quotation with which we begin this article, attributed to Muhammad Ali, has some intuitive appeal, even to people who generally shun personality typologies. The notion that all humanity can be classified in terms of internal and external attributes is intuitively compelling, and the belief that these dimensions may be orthogonal resonates with much folk wisdom. Undoubtedly, most people believe that they have encountered their share of pomegranates and grapes-people in whom the exterior and interior correspond. Indeed, over 35 years of research has shown that social perceivers are all too ready to infer this correspondence (for a review, see Gilbert and Malone, 1995). Nevertheless, recognition of the potential for discrepancies between inner and outer aspects

Joel T. Johnson and Emilie B. Mitchell, Department of Psychology, University of California, Davis; Michael D. Robinson, Department of Psychology, North Dakota State University.

We thank Stacey J. Anderson for her assistance with Study 2.

Correspondence concerning this article should be addressed to Joel T. Johnson, Department of Psychology, University of California, Davis, CA 95616. E-mail: jtjohnson@ucdavis.edu of the self is also an important component of our folk psychology. Although their choice of metaphors may vary from Ali's, many observers may also recall some vivid exemplars of the other two cells. Those who exemplify the proverbial iron hand within the velvet glove are presumably prunes, whereas people with cold hands but a warm heart are somewhat more like walnuts. As intriguing as this typology may be, however, it begs the fundamental question that is the focus of this article. If everyone has an outside layer and an inner core, where do people think that the real person lies? Do people believe that the "true self" is defined by overt actions or by covert thoughts and feelings?

Intuitions are captured by abundant folk maxims, some of which directly respond to this question. The problem is that those answers, although both definitive and obvious, appear to conflict. On the one hand, some adages and figures of speech suggest the primacy of the covert. The above-quoted verse from Proverbs, for example, expresses the rather widely held view that people are defined by what they think. In addition, frequent usage of the metaphor of the heart underscores the prevalence of the notion that emotions also constitute a fundamental aspect of the person. These beliefs, however, clash head-on with other maxims, notably Tolstoy's claim that it is overt deeds (and not covert thoughts and feelings) that reveal the truth about oneself. According to this view, our thoughts gain substance, and tell the world who we really are, only when we convert them into willful action.

If we turn to contemporary theories to decide the question, we find that the distinction between extrinsic and intrinsic motivation (Deci \& Ryan, 1985; Ryan \& Deci, 2003) has some direct relevance. Distasteful activities that are performed solely for extrinsic rewards are by definition inauthentic manifestations of the person. But what of behavior that is intrinsically motivated? Or extrinsically motivated behavior that is later internalized and assimilated 
to the self? In these cases, what best reflects who the person really is - the activity itself or the subjective experience of the actor?

Rogers (1961) offered an unequivocal answer. The real person, he argued, consists of the feelings that underlie "the false front ... this experiencing of feeling is really the discovering of unknown elements of self' (p. 111). When one's authentic feelings are experienced and the true self thus discovered, behavior change will naturally follow. By contrast, Bem (1972) contended that actors, like observers, sometimes infer feelings from observations of behavior. From this perspective, action is the defining manifestation of the self, and a mental state is a simple consequence of watching what one does.

\section{Inferences Based on Verb Type}

Empirical evidence also fails to resolve the conflict. On the one hand, research on the causality implicit in language suggests that people may believe that the authentic self is most revealed by actions. In this connection, an influential article by Brown and Fish (1983) provided evidence of a distinction between verbs describing action and verbs describing mental states. Their studies indicated that people tend to attribute causality for an action to some disposition of the actor but to attribute causality for a mental state to some quality of the stimulus. Brown and Fish proposed an explanation based on the assumptions that social achievers generally make about patterns of covariation. They contended that people vary more in their capacity for action than in their capacity for being acted on and also that people vary more in their capacity for inciting subjective experiences in others than in their capacity for having those experiences.

To illustrate the Brown and Fish (1983) arguments, consider the inferences triggered by this statement: "Simon slanders Siegfried." Because we think that people's capacity (and proclivity) for slander varies more than their capacity for being slandered, we attribute the action to Simon the slanderer rather than to Siegfried the slandered. By contrast, suppose we read that "Simon loathes Siegfried." Because we believe that people's capacity for inciting loathing varies more than their capacity for loathing, the attribution is to Siegfried, the object of loathing, and not to Simon the loather.

Later accounts departed somewhat from the Brown and Fish (1983) explanation. Gilovich and Regan (1986), for example, argued that the crucial element may be whether volition is inferred, not whether actions or mental states are believed to vary more across individuals. Their data indicate that actions are believed to entail more personal choice than mental states, which people view as largely involuntary (see also Johnson, Struthers, \& Bradlee, 1988). They argue that it is this perception of personal choice on the part of the actor that causes attribution of the action to him or her. By contrast, Fiedler and Semin (1988) proposed that causal attributions are influenced by the imagined context that the sentence elicits in readers (i.e., "What happened before?" to instigate the action or the mental state and "What happened afterward?"). The prediction under each of these theoretical explanations, however, is the same as the prediction of Brown and Fish: People will attribute an action to the actor but attribute the mental state of the actor to the external stimulus. Despite exceptions, this general pattern has been repeatedly confirmed (e.g., Au, 1986; Semin \& Fiedler, 1992; for a review, see Rudolph \& Forsterling, 1997).

Evidence also supports a logical corollary to this attribution pattern. If actions are attributed to the agent and mental states are attributed to the stimulus, Simon's actions, compared with his mental states, should be viewed as more informative about the personal characteristics of Simon. Research by Semin and associates (Semin \& Fiedler, 1988; Semin \& Marsman, 1994, 2000) has confirmed that verbs describing a person's actions are considered more informative about a person, leading to stronger dispositional inferences, than verbs describing that person's mental state.

These last studies would seem to point toward an answer to a central question that motivated the present research. People may believe that mental states, as the involuntary products of transient circumstance, provide only unreliable intimations of what an individual is really like. Accordingly, they may conclude that actions are the best indicators of personal authenticity and subscribe to Tolstoy's view that the most basic truths about ourselves are revealed by our chosen deeds.

\section{Evidence for the Perceived Diagnosticity of Mental States}

Despite the elegant methods and frequently replicated findings of verb research, there is reason to doubt the broad generalization that actions always speak louder than feelings. Our recognition of consciousness in other humans is accompanied by the notion that the real person is to be found somewhere within that ongoing stream of consciousness. Like the writer of Proverbs, people may be drawn beneath the surface in their search for the substance of the true self, perhaps intuitively believing that it resides in the heart and mind rather than in behavior.

Andersen and Ross (1984) in fact supported the idea that people, in their quest for the authentic self, turn their attention to the covert aspects of the person. They asked participants what they would rather do to learn what someone else was "really like." Would they want to observe the behavior of a person for a day or learn all the person's private thoughts and feelings for that day? Participants overwhelmingly opted to learn about thoughts and feelings. In a second study involving observation of an interview, interviews emphasizing thoughts and feelings were rated as more informative about the interviewee than were interviews emphasizing the interviewee's behavior. Subsequent research by Andersen and others has indicated that people assign particularly strong importance to internal states (vs. behaviors) when thinking about themselves (Andersen, Lazowski, \& Donisi, 1986; Andersen \& Williams, 1985) or significant others (Andersen, Glassman, \& Gold, 1998; Prentice, 1990).

\section{Overview of Current Studies}

In sum, prior research has supplied grounds for two ostensibly conflicting predictions. The verb studies suggest that actions, which are perceived as more volitional than mental states and more likely to have a dispositional cause, are also likely to be viewed as more diagnostic of the true self. By contrast, the research of Andersen and others (Andersen et al., 1986, 1988; Andersen \& Williams, 1985; Prentice, 1990) suggests an opposite, and paradoxical, result. Although mental states may be viewed as nonvolitional products of external stimuli, they may nevertheless also be viewed as key to who the person really is. In the present studies, we sought to determine whether this apparent conflict between previous findings might be reconciled. We departed from prior verb research by posing questions about the true self, seeking to identify whether participants believed it was best revealed by 
actions or by mental states. Additionally, in Studies 1 and 2 we investigated the role of specific variables-for example, volition, perceived causality, and stability across social interactions-that might influence whether actions or states were viewed as more diagnostic. In Study 3 we used a more open-ended method to examine these issues. Specifically, we asked participants to generate questions that they would pose to another individual to learn about the true self of that person.

Research on the causality implicit in verbs (e.g., Brown \& Fish, 1983) has typically presented brief sentences involving verbs of action or verbs of state and then assessed whether participants attribute causality to sentence subject or sentence object. We used a variation of this procedure in Study 1, in which we presented sentences in pairs. One sentence described an action (e.g., "Tom protects Robert"), whereas the other sentence described the mental state of the actor ("Tom likes Robert"). Participants rated each verb on causality, volition, variability in consensus among actors and experiencers, and, most importantly, the extent to which the action or state was diagnostic of the true self of the actor.

We repeated this procedure in Study 2 but added a condition in which we increased the size of the relevant database. It seemed likely to us that action-state differences in perceived diagnosticity would be affected by information about the chronic dispositional tendencies of the target individual. As we later discuss in greater detail, there were theoretical reasons for expecting people to believe that a chronic mental state is more stable across interactions with others than a chronic action tendency and also for expecting people to believe that the most stable aspects of a person are reliable indicators of that individual's true self. Accordingly, in this condition we described both the action and the mental state as chronic dispositional tendencies of the sentence subject rather than as one-time occurrences.

Study 3, unlike Studies 1 and 2, used an open-ended method to examine participants' views concerning the "stuff" of the true self. Participants wrote questions designed to discover the true self of another person, in this case a hypothetical one. Judges coded the questions according to whether they emphasized observable actions or unobservable mental states, allowing us to examine the relative importance of these categories under these unconstrained conditions. Finally, it seemed to us that participants who attach particular importance to emotional states might be especially likely to believe that unobservable states, more than actions, are diagnostic of the true self. Accordingly, in both Studies 2 and 3, we examined the relation between our primary dependent measures and responses on the Attention to Emotions Subscale of the Trait Meta-Mood Scale (Salovey, Mayer, Goldman, Turvey, \& Palfai, 1995), an instrument that assesses the perceived importance of emotions in both the self and people generally.

\section{Study 1}

Our first objective in Study 1 was to examine a main effect for verb type-an effect that potentially could support either of the two competing hypotheses mentioned at the outset. One hypothesis, generated from research on the causality implicit in language (e.g., Brown \& Fish, 1983; Rudolph \& Forsterling, 1997; Semin \& Marsman, 1994, 2000), predicts that action verbs, which tend to generate dispositional attributions, are seen as more indicative of the true self than state verbs, which tend to generate stimulus attributions. The competing hypothesis, based on research by
Andersen and colleagues (e.g., Andersen \& Ross, 1984), predicts that people believe that the true self is revealed more by private mental states than by covert actions. In addition to assessing these competing hypotheses, Study 1 also expanded on prior research by examining hypotheses concerning the relations among four sets of dependent measures - assessments of the true self, of dispositional causality, of volition, and of the relative variability of actions and mental states across actors and experiencers-that might explain why either actions or mental states are viewed as more diagnostic of the true self.

The dispositional causality hypothesis, derived from verb research, predicts that a tendency to view action verbs as more indicative of the true self is positively correlated with a tendency to believe that actions, more than mental states, are caused by a disposition of the target. The variability hypothesis is derived from Brown and Fish (1983) and relates to their proposal concerning beliefs about covariation. It predicts that both the tendency to attribute more causality to actions and the tendency to see action verbs as more indicative of the true self are related to the belief that people differ more in their action tendencies than in their mental states. Finally, the volition hypothesis, based on the findings of Gilovich and Regan (1986), predicts that the tendency to attribute more dispositional causality to actions as well as the tendency to see action verbs as more indicative of the true self are related to the belief that actions, more than mental states, are under voluntary control. To our knowledge, Study 1 represents the first attempt to assess the relations among variability, volition, and causal attributions in a single design as well as the first attempt to relate these measures to perceptions of the true self.

Our final objective was to examine whether the action-state difference in perceptions of the true self was influenced by congruence-the degree to which the action and the state seem consistent with one another. We hypothesized that when actions are congruent with underlying feelings, both are likely to be perceived as relatively trustworthy and authentic and hence relatively diagnostic of the true self. Actions inconsistent with feelings, however, might be perceived as manipulative and less genuine. Because mental states, by contrast, are seen as relatively involuntary, their perceived authenticity may be less substantially undermined when inconsistent with actions. Accordingly, we predicted that incongruence would reduce the diagnosticity of actions more than the diagnosticity of mental states.

\section{Method}

Overview. In Study 1, we presented a series of 12 sentence pairs. In one sentence in each pair, the verb described the action of a target individual (the sentence subject) toward another person (the sentence object), and in the remaining sentence the verb described the mental state of the target individual that accompanied the action. Common same-gender names (e.g., "Katherine" and "Linda"; "Bill" and "Steve") were used to designate both subject and object. Participants rated the extent to which both the state and the action indicated something about the true self of the target person. In addition, they rated the extent to which both the state and the action were caused by the target person (who was both the actor and the experiencer) or by the other individual (who was the object of both the action and the state). They also rated the extent to which both the action and state were under the voluntary control of the target person as well as the extent to which people varied in their tendency to perform the action and to have the mental experience. The design counterbalanced for order of measures. 
Participants. Participants were 213 undergraduates (132 women and 81 men) at the University of California, Davis. They received extra credit in a psychology class for their participation in the study.

Instructions and dependent measures. In an introductory page of general instructions, we informed participants that "earlier research in psychology has indicated that simple verbs often contain extensive implications" and that the researchers were interested "in studying what certain verbs imply to you." They were told that they would see the same sentence pairs several times and would be asked several sets of questions about the relevant verb in each sentence. Following these general instructions, participants received specific instructions pertaining to each of the four dependent measure sets. These dependent measure sets and accompanying instructions were presented in counterbalanced order.

For the true self measures, participants were told they would be reading a series of sentence pairs in which each sentence in the pair "describes something about the relation between the same two people." After reading each sentence pair (e.g., "Sara helps Amy. Sara is amused by Amy"; "Bill detests Steve. Bill manipulates Steve"), participants were asked to "indicate your belief about whether the described action or experience implies something about the true self - the authentic and fundamental nature-of the person who is the grammatical subject of the sentence." They then rated both the verb of action and the verb of state on separate 9-point scales, with endpoints 1 (it probably is NOT a very good indicator of [name of the sentence subject's-e.g., Sara's] true self) and 9 (it probably IS a very good indicator of [name of the sentence subject's] true self).

For the dispositional causality measures, participants were asked to "indicate your belief about the cause of the described action or experience" that appeared in the sentence. They were requested to rate the "most important cause" of both the action and the state on separate 9-point scales, with endpoints from 1 (something about [name of the sentence subjecte.g., Sara]) to 9 (something about [name of the sentence object-e.g., Amy]).

For the volition measures, participants were asked to "indicate your belief about whether the described action or experience was under the voluntary control of the person who is the grammatical subject of the sentence." After reading each sentence pair, they rated how easy or difficult it was for the sentence subject to control both the action and the state (e.g., "Bill's detesting Steve" and "Bill's manipulating Steve"). The action verb and the state verb were both rated on separate 9-point scales, with endpoints from 1 (probably very easy) to 9 (probably very difficult).

For the variability measures, participants estimated how much individuals vary in their tendency to display the relevant actions and mental states. Participants were not presented with the sentence pairs prior to making their variability ratings. Instead, we asked them to "indicate exactly how much you think people differ from one another in their tendency to experience particular feelings and to act in particular ways." Tendencies in both the relevant actions of the target figures and the relevant mental states were rated on separate 9-point scales, with endpoints from 1 (there is very little difference among people) to 9 (there is a great deal of difference among people). We can conceptualize the variability measure as an assessment of assumptions about a specific kind of covariation: the relative variability in perceived consensus among experiencers versus actors. By using this measure, we assessed the Brown and Fish (1983) proposition that people assume high consensus among experiencers (e.g., almost everyone has the capacity for liking others) but low consensus among actors (e.g., people vary a great deal in their propensity to protect others).

Design. One objective in Study 1 was to examine whether action verbs, which are typically attributed to the person, are seen as more indicative of the person's true self than are state verbs, which are typically attributed to the stimulus. Toward that end, the 12 action verbs and 12 state verbs used in the study were verbs identical or similar to those that other studies suggested tend to elicit the attributions typical of their class (e.g., Au, 1986; Brown \& Fish, 1983; Semin \& Fiedler, 1992; Semin \& Marsman, 1994, 2000). ${ }^{1}$ An additional selection criterion related to our hypothesis that actions would be perceived as relatively less diagnostic of the true self when they were incongruent with the accompanying experiences. To assess this hypothesis, we selected 6 action verbs that suggested a beneficial or helpful action toward the sentence object and 6 that suggested a detrimental or harmful action toward the sentence object. We also selected 6 state verbs that suggested a benign feeling toward the sentence object and 6 that suggested a negative feeling toward the sentence object. We then randomly assigned the 6 verbs in each of these four subcategories to a congruent or incongruent set. Among verbs in the congruent set, each beneficial action verb was randomly matched with a benign feeling verb and each detrimental action verb with a negative feeling verb. Among verbs in the incongruent set, each beneficial action verb was matched with a negative feeling verb and each detrimental action verb with a benign feeling verb. This resulted in a total of six congruent and six incongruent verb pairs. The congruent pairs were protects-likes, apologizes torespects, helps-is amused by, harasses-envies, manipulates-detests, and competes against-fears. The incongruent pairs were: shares with-is angry with, instructs-mistrusts, flatters-hates, defies-admires, teases-is inspired by, and harms-is fascinated by. ${ }^{2}$

All participants rated the same 12 verb pairs on the same four sets of dependent measures. However, the experimental design included several between-participants variables to counterbalance for possible order effects. First, four different orders of presentation of dependent measure sets were counterbalanced across participants. Counterbalancing was done according to a Latin square design such that each dependent measure set appeared in each ordinal position exactly once. Second, the order of action and experience verbs was varied between participants. Half of the participants always received sentence pairs in which the action verb appeared first. Within each dependent measure set, these participants also consistently rated the action verb in the pair before rating the experience verb. The other half of the participants always received sentence pairs in which the experience verb appeared before the action verb. These participants consistently rated the experience verb in the pair before the action verb. Finally, within each of the dependent measure sets, half of the participants rated the verbs in one random order, and the other half rated the verbs in the opposite order.

\footnotetext{
${ }^{1}$ Under the classification system introduced by Semin and Fiedler (1992), the action verbs used in these studies would be classified as interpretive action verbs. Interpretive action verbs involve interpretation as well as description and have generally been associated with attributions to the actor. They are to be contrasted with descriptive action verbs (e.g., call, meet, phone), which represent objective descriptions of common behaviors that are performed by virtually everyone. Descriptive action verbs generally do not have a positive or negative valence, and their interpretation varies widely with the context. It is important to note that the action verb effects that we describe in this article involve only interpretive action verbs. The verbs of mental state would be classified as either state verbs, which refer to unobservable states, or state action verbs, which refer to states that are caused by an observable action. Prior research has indicated that both categories of state verbs are generally associated with stimulus attributions, and the distinction between them does not relate to our hypotheses.

${ }^{2}$ Our assumptions about congruence were validated by a sample of 64 undergraduate judges. For each of the 12 sentence pairs in the study, they rated the extent to which the actions of the grammatical subject of the sentence toward the grammatical object were consistent with the affect of the grammatical subject for the grammatical object (e.g., "Are Bill's actions toward Steve consistent with his feelings about Steve?"). Ratings were made on a 9-point scale from 1 ([The sentence subject's] actions are very inconsistent with his feelings) to 9 ([The sentence subject's] actions are very consistent with his feelings). The mean rating for each of the six congruent pairs (overall $M=7.23$ ) was always above 5, the midpoint of the rating scale, whereas the mean rating for each of the six incongruent pairs (overall $M=3.17$ ) was always below 5 .
} 


\section{Results}

True self ratings. Our main interest related to whether an action or a mental state was seen as more diagnostic of the true self of the target figure. We also examined whether inferences concerning true self diagnosticity might vary with whether the stateaction pair was apparently congruent (e.g., protects-likes) or seemingly incongruent (e.g., flatters-hates). These two variables-verb type (mental state vs. action) and congruence (congruent vs. incongruent)—varied on a within-participant basis. We examined mean true self ratings in a $2 \times 2 \times 2$ (Participant Gender $\times$ Verb Type $\times$ Congruence) univariate analysis of variance (ANOVA) on the verb categories relevant to our hypotheses. Means and standard deviations for this $2 \times 2 \times 2$ design, along with marginals, are presented in Table 1 .

First, the ANOVA revealed the expected main effect for congruence, $F(1,211)=118.38, p<.0001$. Participants believed that both action verbs and state verbs were more reliable indicators of the true self when the action and state were congruent with one another. Second, consistent with the hypothesis derived from verb research (e.g., Brown \& Fish, 1983; Semin \& Marsman, 1994, 2000), but ostensibly inconsistent with the research of Andersen and colleagues (e.g., Andersen \& Ross, 1984), a main effect for verb type indicated that participants generally believed that action verbs were more informative about the true self of the target person than state verbs, $F(1,211)=6.07, p<.015$. This main effect, however, was modified by a Congruence $\times$ Verb Type interaction, $F(1,211)=36.20, p<.0001$, displayed in Table 1 . Although incongruent stimulus conditions reduced the true self ratings of both actions, $F(1,211)=110.71, p<.0001$, and states,

Table 1

Inferences Concerning True Self Diagnosticity as a Function of Verb Type, Congruence, and Participant Gender, Study 1

\begin{tabular}{|c|c|c|}
\hline \multirow[b]{2}{*}{ Congruence } & \multicolumn{2}{|c|}{ Verb type } \\
\hline & Action & State \\
\hline \multicolumn{3}{|c|}{ Men only } \\
\hline \multicolumn{3}{|l|}{ Congruent pairs } \\
\hline$M$ & 6.71 & 5.79 \\
\hline$S D$ & 1.32 & 1.49 \\
\hline \multicolumn{3}{|l|}{ Incongruent pairs } \\
\hline$M$ & 5.74 & 5.43 \\
\hline$S D$ & 1.48 & 1.57 \\
\hline Marginal means & 6.23 & 5.61 \\
\hline \multicolumn{3}{|c|}{ Women only } \\
\hline \multicolumn{3}{|l|}{ Congruent pairs } \\
\hline$M$ & 6.47 & 6.13 \\
\hline$S D$ & 1.17 & 1.22 \\
\hline \multicolumn{3}{|l|}{ Incongruent pairs } \\
\hline$M$ & 5.48 & 5.83 \\
\hline$S D$ & 1.36 & 1.36 \\
\hline Marginal means & 5.98 & 5.98 \\
\hline \multicolumn{3}{|c|}{ Marginals for entire sample $(M s)$} \\
\hline Congruent pairs & 6.59 & 5.96 \\
\hline Incongruent pairs & 5.61 & 5.63 \\
\hline Marginal means & 6.10 & 5.80 \\
\hline
\end{tabular}

$F(1,211)=24.47, p<.0001$, action ratings were reduced significantly more. Accordingly, whereas participants believed that congruent actions were more diagnostic than congruent states, $F(1$, 211) $=30.28, p<.0001$, their diagnosticity ratings did not differ when state and action were incongruent with one another $(F<1)$.

The ANOVA also indicated a significant Participant Gender $X$ Verb Type interaction. Women, compared with men, estimated higher relative diagnosticity ratings for states, $F(1,211)=6.47$, $p<.015$. As indicated by the means displayed in Table 1 , however, women as well as men believed that actions were better indicators of the true self than states when state and action were congruent with one another $(p s<.02)$. There were no other significant effects in the ANOVA. ${ }^{3}$

Ratings on other measures. In examining ratings on other measures - causality, volition, and variability - our primary interest was in determining whether there was a main effect for verb type, as suggested by previous research pertaining to action versus state verbs. Ratings of dispositional causality were reverse scaled so that higher numbers indicated stronger attributions to a disposition of the sentence subject (the target), and ratings on the volition measure were reverse scaled so that higher numbers indicated greater control of the action or experience by the target. On the dispositional causality measure, action verbs $(M=6.10$, $S D=1.12)$ resulted in stronger dispositional attributions than state verbs $(M=3.19, S D=1.21), F(1,211)=623.09, p<.0001$. On the volition measure, participants believed that the target had greater control of actions $(M=5.56, S D=1.34)$ than of states $(M=3.92, S D=1.24), F(1,211)=161.21, p<.0001$. On the variability measure, as predicted by the hypothesis derived from Brown and Fish (1983), participants believed that people generally vary significantly more in their tendencies toward actions $(M=$ $6.04, S D=1.08)$ than in their tendencies related to mental states $(M=5.54, S D=1.15), F(1,211)=49.15, p<.0001$. From the perspective of these analyses, then, all of these variables-attributions of causality, perceptions of volition, and perceptions of variability - could explain why a given action is viewed as more diagnostic of the true self than is a particular mental state.

When gender and congruence were added to the ANOVAs on these measures, the main effects remained significant (all $p s<$ .0001). The three-way ANOVA on dispositional causality revealed no additional effects beyond the main effect for verb type described above. However, other effects did emerge in the ANOVAs on volition and variability. In the volition ANOVA, there was a significant Participant Gender $\times$ Verb Type $\times$ Congruence interaction, $F(1,211)=8.48, p<.004$. In all cells of the design, actions were rated as more controllable than states, but the size of the discrepancy varied with gender and congruence. Specifically, the action-state discrepancy in perceived controllability was greater among male participants in the congruent (vs. incongruent) condition; by contrast, this discrepancy was greater among female participants in the incongruent (vs. congruent) condition. It is important to note, however, that four additional pairwise ANOVAs

\footnotetext{
${ }^{3}$ Subsequent analyses indicated that none of the significant effects were modified by order of dependent measure set or by whether participants rated state before action or action before state. A final set of analyses also indicated that the direction of state-action differences was also not affected by the particular combination of state valence (benign vs. negative) and action (benign vs. detrimental).
} 
revealed that both men and women rated actions as more controllable than states in both congruent and incongruent conditions $(F \mathrm{~s}>31.23, p \mathrm{~s}<.0001)$.

The ANOVA on variability revealed a main effect for congruence, $F(1,211)=8.35, p<.004$, as well as an interaction between congruence and verb type, $F(1,211)=9.64, p<.002$. Although mean variability ratings for action verbs were identical between congruence conditions, the variability ratings for state verbs were higher in the incongruent condition than in the congruent condition. It should be noted that participants did not rate variability in the context of the specific action-state pairings that were presented when they rated the other measures but simply indicated how much people varied in their tendency to perform the action or to experience the state. Accordingly, the congruence-related effects on variability are likely due to differences among the state verbs assigned to congruent versus incongruent conditions. Most important, however, actions were seen as more variable than states in both congruent and incongruent conditions $(F \mathrm{~s}>13.70, p \mathrm{~s}<$ $.0001)$.

Correlations among measures. We next sought to identify the ways in which these action-state differences on dispositional causality, volition, and variability were related to one another as well as the extent to which they predicted participants' general tendency to view actions as more diagnostic of the true self of the target. To examine these questions, we created a difference score on each measure by subtracting ratings pertaining to mental states from ratings pertaining to actions. In all cases, the higher the difference score, the higher the relative ratings of actions. The correlations are displayed in Table 2.

Consistent with the speculations of Gilovich and Regan (1986), analysis of these difference scores revealed a significant positive relation between judgments of volition and attributions of dispositional causality. Participants' tendency to believe that actions are substantially more controllable than states was positively related to their tendency to believe that actions, more than states, are caused by a dispositional property of the sentence subject. There was also a significant positive correlation between the volition and variability difference scores, indicating that participants who showed the strongest tendency to view actions as more volitional (in relation to mental states) also tended most strongly to view actions as more variable. However, the variability and causality difference scores were not related to one another. This latter result provides no support for the Brown and Fish (1983) supposition that actionstate differences in causal attribution are directly influenced by the perceived variability among actors versus experiencers. Finally,

Table 2

Correlations Among Action-State Difference Scores on Measures of Dispositional Causality, Volition, Variability, and True Self Diagnosticity, Study $1(N=213)$

\begin{tabular}{lcccc}
\hline \multicolumn{1}{c}{ Measure } & 1 & 2 & 3 & 4 \\
\hline 1. True Self & - & $.27^{* * *}$ & $.16^{*}$ & .05 \\
2. Causality & & - & $.17^{*}$ & .08 \\
3. Volition & & & - & $.22^{* *}$ \\
4. Variability & & & & - \\
\hline
\end{tabular}

Note. Difference scores were computed by subtracting mean state ratings from mean action ratings on each measure.

$* p<.05 . \quad * * p<.01 . \quad * * * p<.0001$. both the volition and dispositional causality difference scores, but not the variability difference score, were significantly correlated with our measure of foremost interest-the action-state difference in perceived diagnosticity of the true self.

For our last analysis, we regressed the action-state difference score in true self ratings on the difference scores for the other three measures. The regression results suggest a primary relation between the belief that actions are more diagnostic of the true self and the tendency to believe that actions, more than states, are caused by a disposition of the sentence subject. With all three predictors in the regression equation, the relation between the true self difference score and the dispositional causality difference score was significant, $\beta=.25, t(209)=3.69, p<.0001$, whereas the relations between the true self difference score and the volition difference score, $\beta=.11, t(209)=1.62, p>.10$, and between the true self difference score and the variability difference score, $\beta=$ $.01, t(209)=.16, n s$, were not.

\section{Discussion}

In Study 1, we assessed two competing predictions. Prior verb research (e.g., Brown \& Fish, 1983; Rudolph \& Fosterling, 1997) demonstrated that actions, more than mental states, are ascribed to a property of the actor, suggesting that people may also view an action as more diagnostic of the true self. By contrast, Andersen and Ross (1984) indicated that people believe a mental state is more diagnostic. The main effect for verb type supports the first prediction over the second, although our results also indicate that the relative diagnosticity of an action is decreased to the level of a state when state and action are incongruent (see Table 1).

Our other goals in Study 1 were to assess theoretical predictions concerning the relations between volition, variability, and dispositional causality and to assess which of these variables predicted diagnosticity of the true self. Consistent with Gilovich and Regan (1986), participants' tendency to view actions as more likely to be caused by a disposition of the subject is positively related to their tendency to believe that actions are more under the volitional control of the person than are states. Participants also believed that individuals vary more in their actions than they do in their feelings, providing empirical support for the proposal of Brown and Fish (1983). Given the lack of a correlation between variability and dispositional causality, however, there was no support for the Brown and Fish suggestion that schemas concerning variability in consensus have a direct influence on causal attributions.

Finally, our results offer insight as to why people believe that an action, more than a state, may reflect the true self. Whereas participants ascribed a mental state to a stimulus, they attributed an action to a dispositional property of the actor. These judgments of causal responsibility for an action or event are conceptually distinct from judgments of whether the action or event reveals something important about the true self of the target. An observer, for example, might attribute a helpful action to something about the actor, and the actor's emotion to the tragic plight of the victim, yet believe that the emotion, more than the action, reflects a more important and fundamental characteristic of the actor. Our results, however, indicate that the general tendency to believe that an action is more diagnostic of the true self is correlated with a tendency to make stronger dispositional attributions on the basis of an action (versus a mental state). Although true self difference scores are also related to volition difference scores (but not to 
variability difference scores), this relation disappears when causal attributions are controlled. In sum, Study 2 indicated that neither perceptions of what is more controllable nor perceptions of what varies more among persons are reliable predictors of the tendency to believe that actions are more diagnostic of the true self. The strongest predictor, our data suggest, is the tendency to attribute an action to a disposition of the target.

\section{Study 2}

Despite generally clear findings, Study 1 left certain issues unresolved. First, interpretation of the Congruence $\times$ Verb Type interaction is somewhat hindered by limitations of the experimental design. Because verbs were assigned to either congruent or incongruent combinations, verb and congruence were confounded. In Study 2, we rectified this limitation by eliminating the confound. We counterbalanced for congruence across verb type, such that the verbs presented to some participants in congruent combinations were presented to the remaining participants in incongruent combinations.

Most important, we sought to reconcile the apparent inconsistency between Study 1 and prior verb research on the one hand and Andersen and Ross (1984) on the other. In this regard, we noted that prior studies on the causality implicit in verbs (e.g., Brown \& Fish, 1983; Semin \& Marsman, 1994, 2000) differed from Andersen and Ross in at least one important respect. Both Study 1 and the verb research examined the inferences people draw from a single example of a subject-object relation-for example, "Tom likes Robert" and "Tom protects Robert." By contrast, responses in Andersen and Ross were based on a more extensive database. Participants either rated the diagnosticity of actions and states over time-for example, behavior versus thoughts and feelings for a day, or for several months (Study 1), or the informativeness of comparatively large samples of covert or overt behavior (Study 2). We speculated that perceptions about the relative diagnosticity of actions versus states are affected by whether the database consists of a single example or information about a chronic pattern.

In support of our speculations, early research by Abelson and associates (Abelson \& Kanouse, 1966; Gilson \& Abelson, 1965; Kanouse, 1972) suggested that the effect of verb type may differ according to whether one is asked to generalize from a particular instance to broad dispositions in behavior (an inductive reasoning task) or to apply a generalization to predict behavior in a specific situation in the future (a deductive reasoning task). When the task involved inductive reasoning, participants in that research were more willing to generalize from a particular example if the statement involved an action verb than if it involved a state verb. For a deductive reasoning task, however, this pattern was reversed. Participants were more likely to believe that a broad generalization held for a particular instance when the generalization involved a state as opposed to action verb.

We can illustrate this pattern with examples from our own stimulus materials- "Tom likes Robert" and "Tom protects Robert." The findings of Abelson and Kanouse (1966) as well as those of Study 1 suggest that people are more willing to infer that Tom is a generally protective person than that he is a person who generally likes other people. Whereas observers tend to attribute a mental state to transient external stimuli, they believe that the commitment of time and energy inherent in a significant action is likely to reflect an enduring dispositional quality of the actor.
But what if the task involves deductive reasoning, and people, based on their knowledge about Tom's general predispositions both to like others and to protect them, are asked to infer his future behavior toward a specific person? In this case, Abelson and Kanouse's (1966) results suggest that observers are more willing to infer that Tom will like Robert than that he will protect him. Kanouse (1972) explained this phenomenon in terms of systematic action-state differences in resources and opportunities. He suggested that the resources and opportunities for engaging in significant actions are generally more limited than those necessary to experience mental states. Although people may have the resources and opportunities to protect only a few other people, we can like a great many of them. Accordingly, it is a good bet that Tom, assuming that he meets someone named Robert, will like him but not protect him. Even though they have both been described as general dispositions, Tom's tendency to like other people is in this sense more stable across stimuli than is his tendency to protect. At any given moment, in any interaction, it is more probable that Tom will like the other person than that he will engage in protective behavior. An implicit recognition of these relative probabilities may account for a greater willingness of people to apply general statements to particular instances when state verbs, as opposed to action verbs, are involved.

Findings from subsequent studies are generally consistent with these thoughts concerning a deductive reasoning task. Mental states represent a more abstract category than actions, and abstraction generally implies greater stability (Semin \& Fiedler, 1988, 1992). People may therefore tend to regard a general disposition to experience a particular mental state as more stable and more likely to be repeated than any of its specific concrete behavioral manifestations-a prediction also consistent with research by Maass and associates on the linguistic intergroup bias (Maass, 1999; Maass, Salvi, Arcuri, \& Semin, 1989). These considerations have ramifications for judgments of what constitutes the true self. If beliefs about the true self are influenced by beliefs about which aspect of the person is most stable across social experiences, general dispositional tendencies related to mental states may be viewed as more diagnostic of the true self than general tendencies related to actions.

In Study 2, participants estimated the stability of actions and mental states across social interactions. We hypothesized that participants who read about a single example of an action and an accompanying mental state would expect the action, more than the mental state, to generalize to other interactions. By contrast, we expected a different result when both action and mental state were described as dispositional tendencies. We expected participants to believe that a chronic state would be more likely than a chronic action tendency to emerge in a future interaction with a specific person.

We also predicted that between-conditions differences in stability would be related to between-conditions differences in true self judgments. This led to our hypothesis that action-state differences in judgments of the true self would reverse according to whether responses on the stability measure reflected an inductive task (in which conclusions about relative stability were based on a single example) or a deductive task (in which conclusions about relatively stability were based on information about general tendencies). In the inductive task condition, we expected to replicate the action-state main effect of Study 1. By contrast, in the deductive task condition, we expected participants to believe that states are 
more stable and more diagnostic of the true self than actions. Such results could go a long way toward reconciling the apparently divergent findings reported by Brown and Fish (1983) on the one hand and Andersen and Ross (1984) on the other. Finally, as in Study 1, we manipulated state-action congruence to assess our prediction that incongruence would reduce the diagnosticity of actions more than of states.

\section{Method}

Overview. With the important exceptions described here, the basic design of Study 2 was identical to that of Study 1. First, in a new between-participants manipulation of "chronicity," we varied whether participants read sentence pairs that described single examples (e.g., "Megan is bored by Beth. Megan pesters Beth.") or chronic dispositional tendencies of the sentence subject (e.g., "Megan is a person who tends to be bored by other people. Megan is a person who tends to pester other people."). Second, in another between-participants manipulation, we varied whether male or female names were used in the sentences. Third, we counterbalanced our congruence manipulation across verbs. Although all participants read both congruent and incongruent sentence pairs, the verbs that were seen by some participants in congruent combinations were seen by other participants in incongruent combinations. Fourth, although we retained the true self and volition measures examined in Study 1, we added a new measure of perceived stability. Participants in the single example condition estimated the respective probabilities that the described state and action would generalize to interactions with other individuals (an inductive reasoning task). By contrast, participants in the dispositional tendencies conditions estimated the respective probabilities that the described chronic state and action tendencies would be present in a specific future interaction (a deductive reasoning task).

Participants. Participants were 195 undergraduates (146 women and 49 men) at the University of California, Davis. They received extra credit for their participation.

Instructions and dependent measures. With the exceptions noted, the instructions and dependent measures were the same as those of Study 1. In the single example condition, the true self and volition measures had a format identical to that of the first study. In the dispositional tendencies condition, participants rated the extent to which the general tendencies described in the sentences reflected the true self of the sentence subject and were controllable by him or her. On the new stability measure, participants in the single example condition estimated the likelihood that the state and action would be stable across other people (e.g., "Megan is bored by Beth. Megan pesters Beth. How likely is it that Megan is a person who tends to be bored by other people? How likely is it that Megan is a person who tends to pester other people?"). By contrast, participants in the dispositional tendencies condition were asked to imagine a future interaction between the sentence subject and a specific person and to estimate the likelihood that the relevant dispositional tendencies reflected a stable quality that would likely be present in that future interaction (e.g., "Megan is a person who tends to be bored by other people. Megan is a person who tends to pester other people. Suppose Megan meets Beth. How likely is it that Megan will pester Beth? How likely is it that Megan will be bored by Beth?'). Finally, participants identified their gender and, unlike Study 1, their ethnicity. They also completed the Attention to Emotion Subscale of the Trait Meta-Mood Scale (Salovey et al., 1995), which measures individual differences in the importance attached to emotional experience in both oneself and in people generally (e.g., "I pay a lot of attention to how I feel" and "Feelings give direction to life").

Design. Each participant read eight pairs of sentences. One sentence in each pair contained an action verb and one contained a state verb, all different from the verbs used in Study 1. As in Study 1, one half of the sentence pairs were combinations in which the action and state were congruent with one another, whereas the remaining half of the sentence pairs were incongruent combinations. In our counterbalancing procedure, we randomly matched four state verbs with congruent action verbs and the remaining state verbs with incongruent action verbs. These combinations were presented to approximately one half of the participants, who were randomly assigned to that combination set. The congruent combinations viewed by this first set of participants were cooperates with-enjoys being around, gives comfort to-is optimistic about, misleads-despises, and disobeys-dislikes. The incongruent combinations viewed by these participants were defends-is bored by, compromises with-dreads being around, criticizes-trusts, and pesters-cares about. The same verbs these participants viewed in congruent combinations were presented to the remaining participants in randomly matched incongruent combinations, whereas the verbs they viewed in incongruent combinations were viewed by the remaining participants in congruent combinations. The congruent combinations viewed by the second set of participants were defends-cares about, compromises with-trusts, criticizes-dreads being around, and pesters-is bored by, whereas the incongruent combinations were cooperates withdespises, gives comfort to-dislikes, misleads-enjoys being around, and disobeys-is optimistic about.

Approximately half of the participants were randomly assigned to read sentences with male names, and half read the same sentences with female names. As in Study 1, we also counterbalanced for two additional orthogonal between-participants variables: order of dependent measure set (true self ratings first vs. true self ratings last) and order of rating verb in pair (action verb first vs. state verb first). These counterbalancing factors were not of theoretical interest.

\section{Results}

True self ratings. Three variables were of primary theoretical interest. One within-participant variable pertained to whether participants rated actions or mental states, and a second withinparticipant variable pertained to whether the action-state combination was congruent or incongruent. The final variable, a between-participants manipulation, was whether the actions and states were described as single examples or chronic dispositions. True self ratings were averaged within cells of the $2 \times 2 \times 2$ (Chronicity $\times$ Verb Type $\times$ Congruence) design, and an ANOVA was performed on these means. The means and standard deviations of these true self ratings, along with marginals, are displayed in Table $3 .{ }^{4}$

${ }^{4}$ On the basis of their self-categorization, participants were classified as European American $(N=93)$, Asian American $(N=63)$, Hispanic American $(N=15)$, Middle Eastern American $(N=11)$, African American $(N=5)$, or biracial $(N=8)$. We performed a series of ANOVAs on our dependent measures to assess potential interactions between the effects of interest and the between-participants variables, including participant ethnicity. There were no interactions involving participant gender, order of dependent measure set, order of verb ratings, or gender of names in the sentences. In addition, none of the effects related to verb type were modified by the valence of the verb (e.g., whether the state was benign or negative and whether the action was beneficial or detrimental). Accordingly, these variables were not included in subsequent analyses. The analyses did reveal several significant interactions involving participant ethnicity and verb combination set (which verbs participants viewed in congruent combinations and which they viewed in incongruent combinations) on the true self measure ( $p s<.05$ ). Subsequent analyses, however, indicated that all effects involving participant ethnicity were confined to one of the two verb combination sets. Examination of the mean ratings for this verb combination set indicated that Asian Americans in the single example condition, unlike other participants, tended to rate feelings as more diagnostic of the true self than actions but only when feelings and actions were incongruent with one another. Given the unreliability and 
Table 3

Inferences Concerning True Self Diagnosticity as a Function of Chronicity, Verb Type, and Congruence, Study 2

\begin{tabular}{|c|c|c|}
\hline \multirow[b]{2}{*}{ Congruence } & \multicolumn{2}{|c|}{ Verb type } \\
\hline & Actions & States \\
\hline \multicolumn{3}{|c|}{ Single example } \\
\hline \multicolumn{3}{|l|}{ Congruent pairs } \\
\hline$M$ & 5.90 & 5.43 \\
\hline$S D$ & 1.25 & 1.23 \\
\hline \multicolumn{3}{|l|}{ Incongruent pairs } \\
\hline$M$ & 5.54 & 5.11 \\
\hline$S D$ & 1.50 & 1.30 \\
\hline Marginal means & 5.72 & 5.27 \\
\hline \multicolumn{3}{|c|}{ Dispositional tendency } \\
\hline \multicolumn{3}{|l|}{ Congruent pairs } \\
\hline$M$ & 6.32 & 6.45 \\
\hline$S D$ & 1.22 & 1.25 \\
\hline \multicolumn{3}{|l|}{ Incongruent pairs } \\
\hline$M$ & 5.52 & 6.06 \\
\hline$S D$ & 1.35 & 1.22 \\
\hline Marginal means & 5.92 & 6.26 \\
\hline \multicolumn{3}{|c|}{ Marginals for entire sample $(M s)$} \\
\hline Congruent pairs & 6.11 & 5.93 \\
\hline Incongruent pairs & 5.53 & 5.59 \\
\hline Marginal means & 5.82 & 5.76 \\
\hline
\end{tabular}

The ANOVA revealed main effects for chronicity, $F(1,193)=$ $19.38, p<.0001$, and for congruence, $F(1,193)=31.80, p<$ .0001 . Collapsing across verb type, participants were less confident that the information indicated something about the true self of the sentence subject when the information pertained to a single example than when it pertained to dispositional tendencies, and they were also less confident when the action and state were incongruent with one another.

More important, however, both of these variables interacted in the predicted way with verb type. The Chronicity $\times$ Verb Type interaction, $F(1,193)=26.64, p<.0001$, was such that although participants generally viewed actions as more diagnostic than states when the information pertained to a single example (replicating the results of Study 1), they also generally believed that states were more indicative of the true self than actions when dispositional tendencies were described. To follow up this interaction, we conducted separate analyses within each chronicity condition. Whereas in the single example condition participants believed that actions were significantly more diagnostic than mental states, participants in the dispositional tendencies condition believed that chronic states were significantly more diagnostic than chronic actions (both pairwise $p \mathrm{~s}<.001$ ). Additional analyses indicated that the state-action reversal was driven primarily by the effect of chronicity on the perceived diagnosticity of states.

difficulty of interpretation of the ethnicity related effects, participant ethnicity was dropped from further analyses. Aside from its interaction with participant ethnicity, verb combination set did not interact with any effects of interest and was therefore also dropped from subsequent analyses.
Although participants rated states as significantly more diagnostic when they were described as chronic tendencies, $F(1,193)=$ $40.78, p<.0001$, they believed that actions toward a single person were about as diagnostic of the true self as actions described as chronic tendencies, $F(1,193)=1.68, p>.15$. In sum, mental states were more diagnostic of the true self when they were described as dispositional tendencies of the individual, whereas this was not true of actions.

The results also revealed a Congruence $\times$ Verb Type interaction, $F(1,193)=3.74, p=.055$. As in Study 1, incongruence tended to reduce the diagnosticity of actions more than the diagnosticity of states. There was a marginal tendency toward a Chronicity $\times$ Verb Type $\times$ Congruence interaction, $F(1,193)=2.69$, $p<.11$, reflecting the fact that in the dispositional tendencies condition, the diagnosticity advantage for states over actions was strong and significant for the incongruent pairs but weak and nonsignificant for the congruent pairs. There were no other significant effects in the ANOVA.

Ratings on measures of volition and stability across social interactions. We next performed secondary analyses to examine effects related to verb type on our measures of volition and stability. A $2 \times 2 \times 2$ (Chronicity $\times$ Verb Type $\times$ Congruence) ANOVA on mean ratings of volition, reverse scored so that higher numbers indicated greater control, showed a main effect for verb type, $F(1,193)=61.15, p<.0001$, which did not interact significantly with the other variables. Collapsing across the congruence variable, participants consistently believed that actions were easier to control than states, both in the single example condition (for actions, $M=5.61, S D=1.34$; for states, $M=4.63$, $S D=1.43$ ) and in the dispositional tendencies condition (for actions, $M=5.22, S D=1.23$; for states, $M=4.42, S D=1.29$ ).

A similar ANOVA on our measure of perceived stability across social interactions revealed a main effect for verb type, $F(1$, $193)=4.98, p<.03$, such that participants extrapolated more from actions than from states (for means, see Table 4). More important, there was also a Verb Type $\times$ Chronicity interaction, $F(1,193)=80.57, p<.0001$. As hypothesized, the interaction paralleled a similar interaction on true self ratings. When the information pertained to an interaction between the target figure and a single individual, and participants were asked to generalize to dispositional tendencies (an inductive reasoning task), they were more willing to extrapolate from actions than from states. By contrast, in the deductive reasoning task, when the verbs referred to dispositional tendencies of the target figure, and participants were asked to extrapolate to a specific future situation, they were more willing to extrapolate from states than from actions. A Verb Type $\times$ Chronicity $\times$ Congruence interaction, $F(1,193)=11.68$, $p<.001$, indicated that this reversal was more pronounced when state and action were incongruent with one another. More specifically, the stability ratings advantage of actions over states in the single example condition was particularly large when the pairs were incongruent. However, both this preference and the reverse preference in the dispositional tendencies condition were significant in both congruent and incongruent combinations $(p \mathrm{~s}<$ .0001). Notably, comparison of effect sizes indicated that the effect of chronicity on action-state differences (the Chronicity $\times$ Verb Type interaction) was greater on the stability measure $\left(\eta^{2}=.30\right)$ than on the true self measure $\left(\eta^{2}=.12\right)$.

We followed up the Verb Type $\times$ Chronicity interaction with separate pairwise comparisons for each verb type. Paralleling 
Table 4

Inferences Concerning Stability as a Function of Chronicity, Verb Type, and Congruence, Study 2

\begin{tabular}{|c|c|c|}
\hline \multirow[b]{2}{*}{ Congruence } & \multicolumn{2}{|c|}{ Verb type } \\
\hline & Actions & States \\
\hline \multicolumn{3}{|c|}{ Single example } \\
\hline \multicolumn{3}{|l|}{ Congruent pairs } \\
\hline$M$ & 5.87 & 5.41 \\
\hline$S D$ & 1.39 & 1.37 \\
\hline \multicolumn{3}{|l|}{ Incongruent pairs } \\
\hline$M$ & 6.11 & 5.15 \\
\hline$S D$ & 1.46 & 1.27 \\
\hline Marginal means & 5.99 & 5.28 \\
\hline \multicolumn{3}{|c|}{ Dispositional tendency } \\
\hline \multicolumn{3}{|l|}{ Congruent pairs } \\
\hline$M$ & 6.42 & 6.78 \\
\hline$S D$ & 1.35 & 1.26 \\
\hline \multicolumn{3}{|l|}{ Incongruent pairs } \\
\hline$M$ & 5.93 & 6.43 \\
\hline$S D$ & 1.39 & 1.21 \\
\hline Marginal means & 6.18 & 6.61 \\
\hline \multicolumn{3}{|c|}{ Marginals for entire sample $(M s)$} \\
\hline Congruent pairs & 6.15 & 6.10 \\
\hline Incongruent pairs & 6.02 & 5.79 \\
\hline Marginal means & 6.09 & 5.95 \\
\hline
\end{tabular}

results on true self ratings, participants extrapolated more from information about states in the dispositional tendencies condition than in the single example condition, $F(1,193)=60.63, p<$
.0001, but were equally willing in the two conditions to extrapolate on the basis of actions, $F(1,193)=1.08, p>.30$. There were no other significant effects in the ANOVA.

Mediation of action-state differences. As in Study 1, we created difference scores to reflect the difference between the ratings of actions and states (i.e., action means minus state means). The difference scores in both the single example and dispositional tendencies conditions are graphically illustrated in Figure 1. Consistent with the ANOVA results, this figure shows that in the dispositional tendencies condition, states (relative to actions) were viewed as more stable and more diagnostic of the true self. By contrast, in the single example condition, these action-state differences were reversed. Actions, however, were viewed as more volitional in both conditions. Notably, neither the true self and volition difference scores $(r=-.06)$ nor the volition and stability difference scores $(r=.00)$ were related. By contrast, there was a correlation between the true self and stability difference scores $(r=.43, p<.0001)$. Participants who showed the strongest tendency to believe that actions were more stable than mental states also tended to judge actions as relatively more diagnostic of the true self. Given this correlation, and given the parallel Chronicity $\times$ Verb Type interactions on stability and true self ratings, we examined whether action-state differences in stability played a significant role in mediating action-state differences in perceived diagnosticity of the true self.

Baron and Kenny (1986) set out criteria for a test of mediation. First, the independent variable (here, chronicity condition) must influence the dependent variable (here, action-state differences in true self ratings). Second, the independent variable must also influence the proposed mediator (here, action-state differences in stability across interactions). Third, the mediator should remain significant in a multiple regression in which the dependent variable

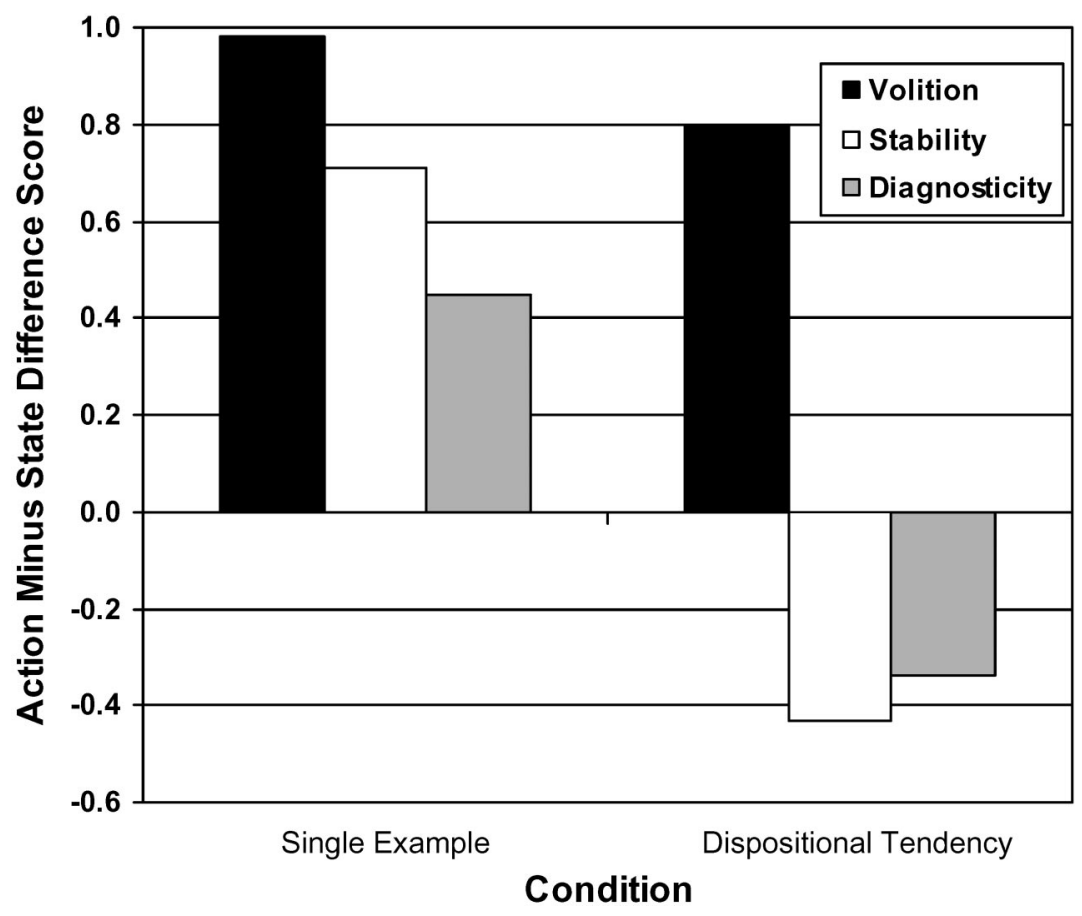

Figure 1. Action minus state difference scores by chronicity, Study 2. 
is regressed on both the independent variable and the mediator, and the effect of the independent variable must be reduced or eliminated. Finally, a Sobel test (Sobel, 1982; see also Preacher \& Leonardelli, 2003) can also be performed to determine whether the mediation is significant.

Linear regressions on the responses of our participants confirmed our ANOVA results that chronicity condition (coded as dispositional tendency $=0$, single example $=1$ ) affected both the true self difference score, $\beta=.35, t(194)=5.16, p<.0001$, and the stability difference score, $\beta=.54, t(194)=8.98, p<.0001$. In a test of the third criterion, when both predictors were entered into the regression equation, the stability difference score predicted the true self difference score, $\beta=.34, t(193)=4.39, p<.0001$, and the effect of the independent variable, $\beta=.17, t(193)=2.15$, $p<.04$, was reduced from when it was the lone predictor. A Sobel test confirmed that this reduction was significant $(z=3.94, p<$ $.0001)$. These results support the idea that inferences of relative stability play an important role in partially mediating the impact of database size (i.e., a single example vs. evidence of chronic dispositional tendencies) on action-state differences in diagnosticity of the true self.

To examine further the relations among ratings of stability, volition, and the true self, we performed another set of correlational analyses. Recall that participants rated each of the 16 verbs on these three measures. Using verb as the unit of analysis, we computed the correlation between stability and true self ratings as well as between volition and true self ratings for each participant in our study. We then converted these correlations to Fisher's $z$ scores to assess whether the mean correlation differed significantly from zero. Our analyses indicated that there was no significant relation between the extent to which an action or state was believed to be under voluntary control and the extent to which it was perceived to be diagnostic of the true self (mean $r=.04$ ). There was, however, a positive relation between the estimated stability of an action or state across social interactions and its true self rating $(r=.27, p<.0001)$. Actions and states that were rated as more stable were also rated as more diagnostic of the true self.

In a final analysis, we examined the correlation between scores on the Attention to Emotion Subscale of the Trait Meta-Mood Scale (Salovey et al., 1995) and the action-state difference score for true self ratings. This correlation did not approach significance in either the single example condition $(r=.05)$ or the dispositional tendencies condition $(r=.03)$.

\section{Discussion}

Consistent with Study 1, the results of Study 2 show that incongruence between states and actions reduces the perceived diagnosticity of actions more than the perceived diagnosticity of states. More important, the Study 2 findings reveal the predicted Chronicity $\times$ Verb Type interaction and provide some insight into the mediation of this effect. In the first study, participants showed a general tendency to believe that an action generally reveals more about the true self than does the accompanying mental state-a tendency related to the belief that an action, more than a state, is caused by a dispositional property of the target figure. Like Study 1 participants, participants in the single example condition of Study 2 also tended to believe that actions are more diagnostic of the true self. However, responses differed in the other condition of Study 2, where both state and action verbs were described as dispositional tendencies. With dispositionality held constant, participants believed that tendencies toward states were more diagnostic of the true self than were tendencies toward actions.

This between-conditions reversal was paralleled by a similar between-conditions reversal in the perceived stability of actions versus states. Participants believed that a single instance of an overt behavior would generalize more to other social interactions than would a single instance of a mental state. By contrast, when both action and state were described as dispositional tendencies, participants believed that a chronic mental state would be more likely to occur in the context of a particular social interaction than would a chronic behavior. Our correlational analyses suggest that assessments of the true self of another individual are at least partially mediated by this action-state reversal in perceived stability. Participants, it appears, may tend to equate the true self with that aspect of the self that is most likely to be present across multiple social interactions, whether that tendency is an action or a mental state.

These data suggest that one's concept of the true self of another person is influenced in predictable ways by information about the social interactions of that individual. The relative diagnosticity of actions versus states, however, varies with the size of the relevant database. Whereas people may tend to believe that a mental state that is experienced in the context of a single interaction is a relatively transient phenomenon, they may also believe that a chronic mental state is more stable than a chronic tendency toward action. Variations in database size also help to explain the previously discussed discrepancy between prior verb research, which has invariably involved single examples of subject-object relations, and the findings of Andersen and Ross (1984), which involved participant consideration of more extensive information.

Finally, one of the most striking and important aspects of both studies is their failure to identify a consistent positive relation between judgments of volition and true self diagnosticity. Although our between-participants analysis in Study 1 indicated that action-state differences on these measures were correlated, this relation disappeared when perceptions of dispositional causality were controlled. In Study 2, parallel between-participants correlations showed no significant relation between the two kinds of judgment. In addition, our within-participant analysis of verb ratings also indicated no significant relation between the perceived volition of an action or state and its perceived diagnostic value. Indeed, Study 2 indicated that states, although consistently viewed as less controllable than actions, are also consistently viewed as more diagnostic than actions when both are described as dispositional tendencies.

\section{Study 3}

In Study 3, we used a very different methodology to examine action-state differences in participants' conceptions of the true self. Andersen and Ross (1984, Study 2) instructed participants to emphasize either cognitive-affective or overt behavioral information when they answered structured interview questions about themselves. Study 3 in effect stood this research paradigm on its head. Instead of assessing the perceived diagnosticity of interviewees' answers to predetermined questions, we analyzed the questions that our participants, as interviewers, spontaneously generated to determine the true self_- "the authentic and fundamental nature"- of someone else. This methodology differed from that 
used in previous studies in that participants were not limited to a forced choice between the dichotomous categories of thoughts and feelings versus behavior. We deliberately avoided providing cues or suggestions about the nature of the questions, and we imposed no limitations on their subject matter. Because the questionnaires were anonymous, and the questions were not actually posed to another individual, the potential influence of perceived social desirability and fear of embarrassment was minimized. This procedure allowed us to examine participants' a priori notions, uninfluenced by suggestions provided by the experimenter, about the true self of a prototypical other. With participants instructed to assume that the other person would draw on his or her entire database of personal knowledge in answering the questions, we expected results to be consistent with those of the dispositional tendencies condition of Study 2. Specifically, we expected the questions to focus more on tendencies in covert than overt behavior. We also examined whether this predicted tendency was related to individual differences in attention to emotion.

\section{Method}

Participants were 70 undergraduates (54 women and 16 men). They received extra credit in a psychology course for their participation in the study. All participants received a questionnaire entitled "Discovering the True Self," with the following instructions:

How do people learn what others are really like? How do they go about discovering the "true self"- the authentic and fundamental nature - of another human being? We would like to learn your ideas on this subject. Imagine that you were allowed to interview a person whom you had never met before, and that you were allowed to ask the person all the questions that you wanted to ask. Imagine also that the person will answer every question completely and in an absolutely truthful way, regardless of the subject matter of the question, and that the person will never hide any secrets from you. In order to discover the "true self" of the person, what questions would you ask? Please take the time to list at least ten of these questions below.

Participants then completed a second page on which they identified their gender and ethnicity and completed the Attention to Emotion Subscale of the Trait Meta-Mood Scale (Salovey et al., 1995). This instrument allowed us to assess whether participants who attended more to their own subjective experience also tended to view mental states as more diagnostic of the true self.

\section{Results and Discussion}

Six undergraduate raters, all uninformed about the study and blind to the hypotheses, independently assessed the degree to which questions referred to private mental states versus observable actions. Questions were classified using a simple three-category classification system based on criteria derived from Andersen et al. (1998). Questions were classified as Category 1 if they referred exclusively to feelings, thoughts, emotions, or characteristics that were not necessarily observable by someone else. Questions were placed in Category 2 if they mentioned unobservable events or unobservable characteristics that would otherwise be placed in Category 1 and also mentioned behaviors or characteristics that could be observed by others who were present at the time. Finally, questions were placed in Category 3 if they referred exclusively to observable behaviors or characteristics. Nearly all participants wrote at least 10 questions, but judges rated only the first 10 . Alphas, computed on judgers' ratings for each of the questions (numbered 1-10 in the order in which questions were listed by participants) were uniformly high, ranging from .86 to .92 .

To assess whether most questions pertained to private mental states, we computed 60 different chi-squares_one for each rater for each of the 10 questions. The pattern across both raters and questions was largely invariant. Category 1 questions, which pertained exclusively to nonobservable mental states or characteristics, were most common in 56 of the 60 analyses. In 53 analyses, the between-categories difference was significant at at least the .05 level, $\chi^{2} \mathrm{~s}(2, N=70)>6.02$, and in 45 analyses it was significant at the .001 level, $\chi^{2} \mathrm{~s}(2, N=70)>13.40 .{ }^{5} \mathrm{In}$ all but 6 of the cases, Category 2 questions, which mentioned both mental states and observable behavior, were next most common. In sum, of the almost 700 questions judged by each rater, raters placed an average of 389.8 questions in Category 1, 202.2 questions in Category 2, and 104.3 in Category 3.

There was additional evidence, however, that the tendency to generate questions pertaining to private mental states was stronger among participants who assigned more importance to their own subjective experience. The correlation between participants' scores on the Attention to Emotion Subscale $(M=4.01)$ and participants' mean categorization ratings for all 10 questions $(M=1.59)$ was $r=-.33(p=.006)$. Participants who attended to and valued emotions more, both within themselves and within others, displayed the greatest tendency to ask questions that were suggestive of the belief that one's true self consists of private mental states. Neither gender nor ethnicity was related to the nature of the questions.

\section{General Discussion}

These studies sought evidence bearing on a fundamental question in person perception: Do people believe that the true self of an individual is revealed more by the person's actions or by the person's mental states? In answering this question, we attempted to reconcile two apparently contradictory sets of findings-research suggesting that action verbs lead to stronger dispositional attributions than state verbs and research suggesting that thoughts and feelings, more than actions, are believed to reflect the true self. In Study 1, we demonstrated not only that verbs of action are associated with stronger dispositional attributions but also that a single example of an action is generally viewed as more diagnostic of the true self than a single example of a mental event. The Study 1 results also indicate that the action-state difference in dispositional causality was the strongest predictor of the action-state difference in perceived true self diagnosticity. Neither our measure of volition nor our measure of variability among actors versus experiencers predicted ratings of the true self when inferences of dispositional causality were controlled.

In Study 2, we used a different set of verbs. We also dropped the dispositional causality and variability measures used in Study 1 and added a new measure that assessed perceived stability across social interactions. Results in the single example condition of Study 2 replicated the action-state differences that we found in Study 1. Replicating the pattern of Study 1, participants in Study

\footnotetext{
${ }^{5}$ For the first 7 questions, $N=70$. However, because several participants wrote fewer than 10 questions, the $N$ s for the final three questions ranged from 66 to 69 .
} 
2 tended to view actions as relatively less diagnostic when state and action were incongruent with one another. In addition, however, we found that participants in the dispositional tendencies condition of Study 2 believed that a chronic mental state is more diagnostic of the true self than is a chronic tendency toward an action.

Under the open-ended format of Study 3, participants listed the questions they would pose to another individual in order to gain insight into the true self of that person. They were instructed to assume that the other person would draw from his or her entire database of personal knowledge in answering the questions. Given this unrestricted potential database, participants formulated more questions pertaining to unobservable mental states than questions pertaining to observable actions, although this effect was moderated by individual differences in attention to emotion.

The answer to the question about the relative influence of actions and states accordingly appears to be a qualified one. Sometimes people believe that actions are more diagnostic, and sometimes they believe that mental states are more diagnostic. One important factor that influences these judgments is the size of the relevant database. Although people may believe that a single action is more diagnostic than the accompanying mental state, they also believe that evidence of a chronic state is more revealing of the true self than is evidence of a chronic action tendency. This effect of database size, our results suggest, is partially mediated by inferences concerning the relative stability of actions and states. Our findings concerning mediation also help to reconcile the ostensibly conflicting results of prior research.

\section{Reconciling Prior Research: The Influence of Inferred Stability}

Participants believe that an action of a target figure toward a specific individual is more likely to generalize to other social interactions than is the mental state that accompanies that action. By contrast, they also believe that the target figure is more likely to experience a chronic mental state in the context of a specific future interaction than to manifest a particular action tendency. Controlling for action-state differences on this stability measure significantly reduces the effect of the chronicity variable on action-state differences on the true self measure. This indicates that beliefs about relative stability, as evidenced by consistency across social interactions, are significant mediators of beliefs about the true self. The aspect of the self that is most likely to be present across occasions is the aspect that people generally believe constitutes the authentic and fundamental nature of the person.

These results help to explain why people believe that action verbs are more informative than state verbs (e.g., Semin \& Marsman, 2000) but also believe that revelations concerning thoughts and feelings are more informative than revelations concerning behavior patterns (e.g., Andersen \& Ross, 1984). Because people believe that an isolated action will generalize more to other situations than will an isolated mental event, actions are more diagnostic of the true self when there is relatively little information about the person. However, when there is ample basis for dispositional inferences concerning both overt and covert characteristics, people believe that covert characteristics represent a more stable component of the personality and hence a more important component of the true self.
We return now to an example mentioned above. Suppose we learn not only that Simon loathes and slanders Siegfried but that Simon is a person who tends to loathe and slander others as well. We may now believe that Simon's loathing represents a more important component of his true self than his slandering, in part because the mental state of loathing is more likely to be present across occasions than any of the numerous concrete manifestations of that state (e.g., his slandering, slapping, or smiting Siegfried or running Siegfried off the road in his sport utility vehicle). Similarly, if we learn not only that Simon likes Siegfried but that he tends to like others, too, we may define Simon more as a person who thinks warm and charitable thoughts than as someone who displays specific manifestations of warmth or charity.

Such conceptualizations may have significant pragmatic value. None of the distasteful concrete manifestations of loathing may be particularly likely, and all of them may be less likely than loathing itself. Nonetheless, any one of them (including running the hapless Siegfried off the road) is generally more likely to be displayed by someone given to loathing than by someone inclined to like most other people. Conceptualizing a person in terms of abstract and stable mental states, that is, may facilitate the prediction of many concrete manifestations of that state.

Finally, it is noteworthy that perceptions of what is diagnostic of the true self, although related to inferences of stability, are not based on perceptions of volition. Consistent with Gilovich and Regan (1986), volition ratings were related to attributions of causality in Study 1. However, perceived volition was not related to judgments of the true self when dispositional causality was controlled. In Study 2, neither between-participants correlations nor within-participant correlations between volition and judgments of true self diagnosticity were significant. In sum, by comparing judgments of volition and true self diagnosticity in these studies, we obtained clear evidence of a paradox. Although participants consistently believed that actions are more under the willful control of the individual than states, they also believed that states are more diagnostic than actions when both are described as dispositional tendencies. In other words, these participants believed that the best indicators of the authentic self are not the products of personal choice but reactions over which the individual may exert relatively little voluntary control. Consistent with a widely used metaphor, these data suggest that people may view the true self as an entity to be "discovered" rather than created through an effort of will.

\section{Caveats and Additional Issues}

Because both stability and true self ratings are dependent measures, it might be argued that the effect of chronicity on inferences of stability is mediated by its effect on judgments of the true self rather than the other way around. We think that this is unlikely for at least two important reasons. First, our comparison of effect sizes indicates that the effect of chronicity on action-state differences in stability is greater than its effect on action-state differences in ratings of the true self. Second, the mediation by stability model is consistent with our a priori hypotheses and our theoretical reasoning and provides a more plausible explanation for the chronicity effect. Participants tend to view a single example of a mental state as the transient product of the external stimulus, believing that a single action is more likely to generalize to other interactions. However, they also think that a chronic mental state is more likely 
to be present across interactions than a chronic behavior. Because people believe that what is present across occasions is likely to be a "real" and important component of the personality, they infer authenticity from stability. Without positing a mediating role for stability, it is difficult to explain why participants believe that a single action may reveal the person more accurately than the accompanying mental state but nevertheless believe that a chronic state is more diagnostic of the person than a chronic behavior.

Our results, however, do not provide definitive evidence that judgments of stability precede judgments of authenticity. Many trait inferences are products of a rapid, virtually automatic process (Gilbert \& Malone, 1995; Smith \& Miller, 1983), and it is unlikely that inferences about the true self are always contingent on conscious consideration of the extent to which a particular trait might generalize across social interactions. Beliefs about the true self may also be influenced by other important factors, and such beliefs, once formed, may affect inferences of stability. The temporal order in which these judgments occur is therefore a matter for further research.

Unlike participants in Studies 1 and 2, people in the course of everyday life do not generally encounter others with labels that categorize either their actions or their mental states (e.g., "I like Sarah" or "I protect Robert"). Instead, people frequently make these categorizations on their own, and the way in which they derive these beliefs is of course an important subject for social cognition research. The focus of these studies, however, was not on how people acquire their beliefs about the actions and mental states of other people but on the relative diagnostic significance of the beliefs that they have acquired.

Viewed from this perspective, the results of our experimental tasks have clear relevance to judgments in more naturalistic contexts. For example, consider the inferences people make when an angered football fan shouts some epithets at the referee. Is the fan's true self revealed more by his anger or his cursing? And what of the inferences made by the fan's longtime acquaintances, who are familiar both with his chronic anger and his habitual tendency to curse? In our studies, we were able to investigate such questions under tightly controlled conditions.

We again caution that our data do not support the claim that stability is the only variable that influences action-state differences in perceptions of authenticity. Both Studies 1 and 2 indicate that action-state congruence may also play a role, and our research, as previously noted, does not foreclose the possibility that other important variables may be involved as well. The mediationby-stability model, for example, does not provide a readily apparent explanation for the Study 3 finding that individuals who attach greater importance to emotional experience pose more questions that focus on private aspects of the self. In addition, we do not argue that chronic mental states are invariably more stable than chronic action tendencies. Indeed, we can envision certain cases in which the opposite may well be true. Consider the hypothetical example of Jack the novelist, who writes compulsively regardless of his mental state. ${ }^{6}$ Jack writes when he is in despair, and he also writes when he feels exhilarated. If his overt behavior is in fact more stable than his accompanying subjective experience, and stability influences perceptions of authenticity, would not his acquaintances believe that his writing, and not his thoughts and feelings, best reflects the authentic Jack?

Although his acquaintances might well believe that Jack is best defined by his writing, our results suggest that his case may be more the exception than the rule. Although some dispositional action tendencies are undoubtedly more consistent than some dispositional mental states, our Study 2 participants believe that dispositional mental states are generally more stable — a belief that for reasons already discussed may have some veridical basis. This may even be true in the case of Jack, if only we define his subjective experience at a higher level of abstraction. If Jack consistently experiences strong emotions, whether positive or negative, we might think of him as "moody" or "intense." Because his intense feelings, if we collapse across valence, may be more pervasive across occasions than his writing, his acquaintances might come to view his intensity as more diagnostic of his authentic self.

Finally, we discuss several additional caveats to our results. First, the correlational analysis in Study 3 indicated that the clear preference for questions that focused on private aspects of the self was even stronger among participants who scored high on the Attention to Emotion Subscale (Salovey et al., 1995). Participants in Study 2 also completed this instrument, but their responses on it were unrelated to other measures. Why did these individual differences emerge in Study 3 but not in Study 2? We suspect that it was because the question composition task of Study 3 required that participants devote a relatively great amount of time and effort to considering the essential nature of the self. It is perhaps primarily in such a context that individual differences related to the importance assigned to subjective experience are likely to play a significant role.

Taken together, the results demonstrate the perceived diagnostic significance of mental states. More specifically, however, they suggest that emotions, a particular subcategory of mental states, may be an important key to perceived authenticity. Fifteen of the 20 different state verbs used in Studies 1 and 2 are classified as emotions by Shaver, Schwartz, Kirson, and O'Connor (1987); de Rivera (1977); or both, and two of the remaining five (detests and despises) have a synonym (loathing) on the Shaver et al. list. The extent to which other subcategories of mental states (e.g., less affectively charged cognitions and beliefs) may differ from emotions in their diagnostic value is a subject for further research. However, the present analysis does suggest that people believe that chronic emotion states are particularly important in revealing the true self of an individual.

A remaining issue concerns whether the present studies have significant implications concerning self-perception. Prior studies (e.g., Johnson, 1987; Johnson et al., 1988; Prentice, 1990; Pronin, Kruger, Savitsky, \& Ross, 2001) have suggested that the tendency to believe that mental states are especially diagnostic of the person might be particularly true in the context of self inference. However, the magnitude and mediation of such actor-observer differences also remains a matter for further research.

A final issue concerns potential cross-cultural differences in the inference of authenticity. Although we found no reliable effects relating to the ethnic heritage of our participants, prior research has suggested that conceptions of the self may well vary between individualistic and collectivistic cultures. Persons in collectivistic cultures tend to view the self as a relatively interdependent entity, emphasizing the importance of relations with others and of tailoring overt behavior to maintain close intergroup harmony (Markus

\footnotetext{
${ }^{6}$ We are grateful to an anonymous reviewer for suggesting this example.
} 
\& Kitayama, 1991). Such tendencies might lead one to predict that individuals from a collectivistic culture define the true self more in terms of observable behavior toward other people than in terms of covert feelings. Paradoxically, however, this very inclination to modify observable actions to accord with the situational mandate might also be seen to imply the opposite prediction. If, as Suh (2002) suggested, the behavior of individuals in some collectivistic cultures (e.g., Korea) displays relatively little cross-situational consistency, such individuals might tend to view the true self more in terms of covert feelings, which presumably vary less with the situational context. In either case, future cross-cultural studies might well identify significant cultural differences in inferences about the true self.

\section{Consequences of Conceptualizing Persons in Terms of Mental States}

Conceptualizing individuals in terms of mental states may, as we argue above, have some utility in predicting as well as understanding behavior. These pragmatic advantages aside, however, there are easily discernable reasons why people seem generally inclined to think of each other in this way. Despite their capacity for mindless action, human beings are characterized by an ongoing stream of consciousness. At any given moment during waking hours, it is likely that they are thinking or feeling something even though they may be doing nothing. In this sense, they are thinkers and feelers more than they are doers, and they define individuals in terms of that ongoing experience of thoughts and feelings. It is also somewhat difficult to envision a world in which things are otherwise, one in which people define each other entirely in terms of what they do rather than what they think and feel and base their concepts of love and malice only on behavioral manifestations. Indeed, this may be a reason that behaviorism, which neglects thoughts and feelings, is ultimately so dissatisfying to many psychologists.

The prevalence of people's tendency to judge authenticity on the basis of mental states, and particularly on the basis of emotions, is perhaps best exemplified by their abundant reliance on the metaphor of the heart. Probably because of the salient changes in heart rate that accompany strong emotion, people still conceptualize the heart, if only metaphorically, as the locus of spontaneous feeling. If this spontaneous feeling is deemed benign (e.g., despite your gruff exterior, you have a heart of gold), you are a real and likeable human being. By contrast, if someone calls you coldhearted, you have just received what is perhaps the ultimate condemnation. Intriguingly, the desires of the heart, although they may form the definitive basis for judgment of the person, are also frequently viewed as beyond volition and perhaps even beyond the pale of personal responsibility. Woody Allen, in discussing his relationship with Soon-Yi Previn, summed it up: "The heart wants what it wants. There's no logic to those things. You meet someone and fall in love and that's that" (Isaacson, 1992).

Despite the predominance of these folk concepts, a case might still be made that actions sometimes should in fact speak louder than thoughts or emotions and that feelings not accompanied by the appropriate behavior are meaningless things indeed. The incessant irritation of the curmudgeon, who grumbles constantly but does nothing particularly harmful, may be far less dangerous to fellow beings than the imprudent behavior of the well-intentioned person of action. Conversely, the reasoned choices of the hard- nosed pragmatist may in the long run be far more beneficial than the efforts of the kind-hearted bumbler. From a purely pragmatic standpoint, then, one can argue that it is sometimes more reasonable to define others by what they do to us than by what they feel about us and to judge them by their actions instead of their inner state. In the same vein, it may sometimes be more reasonable to define ourselves by what we can control and not by feelings that are instigated by external stimuli.

This issue, of course, has some real-world relevance and consequence. In one rather informative example, the matter was addressed, if only obliquely, in the presidential debates before the 2000 election. The transcripts show that in those debates, George W. Bush made frequent use of the metaphor of the heart (e.g., children, he said, can "have their heart turned dark as a result of being on the Internet"). In both the second and third debates, Bush also described a biblical injunction to "love your neighbor like you would like to be loved yourself," and referred to his view that "that's where society must head if we're going to be peaceful and prosperous" (Commission on Presidential Debates, 2004). Vice President Gore responded that he also believed in the Golden Rule, but he was mistaken in his attribution of Bush's advice to love your neighbor. The Golden Rule, from the Sermon on the Mount, is the mandate to "Do unto others as you would have them do unto you." It is all about action, whereas Bush's version was all about mental states.

At another point in the debate, after Bush denied that the prevalence of Texas children without health insurance made him a "hard-hearted person," Vice President Gore responded, "It's not a statement about his heart. I don't claim to know his heart. . . but I think it's about his priorities" (Commission on Presidential Debates, 2004). In the remainder of the campaign, Gore, who was frequently lambasted in the media for an alleged lack of spontaneous feeling, continued to address priorities. Bush, by contrast, continued to make generous use of the metaphor of the heart. ${ }^{7}$ Rather than indulge in any counterfactual thinking, we conclude with only a simple observation: Elections are never solely about priorities. They also involve some judgments about the heart.

\footnotetext{
${ }^{7}$ See Lowry (2001) for an illuminating discussion of Bush's abundant use of the metaphor of the heart.

\section{References}

Abelson, R. P., \& Kanouse, D. E. (1966). Subjective acceptance of verbal generalizations. In S. Feldman (Ed.), Cognitive consistency (pp. 171197). San Diego, CA: Academic Press.

Andersen, S. M., Glassman, N. S., \& Gold, D. (1998). Mental representations of the self, significant others, and nonsignificant others: Structure and processing of private and public aspects. Journal of Personality and Social Psychology, 75, 235-246.

Andersen, S. M., Lazowski, L. E., \& Donisi, M. (1986). Salience and self-inference: The role of biased recollections in self-inference processes. Social Cognition, 4, 75-95.

Andersen, S. M., \& Ross, L. (1984). Self-knowledge and social inference: I. The impact of cognitive/affective and behavioral data. Journal of Personality and Social Psychology, 46, 280-293.

Andersen, S. M., \& Williams, M. (1985). Cognitive/affective reaction in the improvement of self-esteem: When thoughts and feelings make a difference. Journal of Personality and Social Psychology, 49, 10861097.
} 
Au, T. K. (1986). A verb is worth a thousand words: The causes and consequences of interpersonal events implicit in language. Journal of Memory and Language, 25, 104-122.

Baron, R. M., \& Kenny, D. A. (1986). The moderator-mediator variable distinction in social psychological research: Conceptual, strategic, and statistical considerations. Journal of Personality and Social Psychology, 51, 1173-1182.

Bem, D. J. (1972). Self-perception theory. In L. Berkowitz (Ed.), Advances in experimental social psychology (Vol. 6, pp. 2-62). New York: Academic Press.

Brown, R., \& Fish, D. (1983). The psychological causality implicit in language. Cognition, 14, 237-273.

Commission on Presidential Debates. (2004). 2000 debates [Transcripts]. Available from http://www.debates.org

Deci, E. L., \& Ryan, R. M. (1985). Intrinsic motivation and selfdetermination in human behavior. New York: Plenum Press.

de Rivera, J. (1977). A structural theory of the emotions. Psychological Issues, 10(4, Monograph No. 40).

Fiedler, K., \& Semin, G. R. (1988). On the causal information conveyed by different interpersonal verbs: The role of implicit sentence context. Social Cognition, 6, 21-39.

Gilbert, D. T., \& Malone, P. S. (1995). The correspondence bias. Psychological Bulletin, 117, 21-38.

Gilovich, T., \& Regan, D. T. (1986). The actor and the experiencer: Divergent patterns of causal attribution. Social Cognition, 4, 342-352.

Gilson, C., \& Abelson, R. P. (1965). The subjective use of inductive evidence. Journal of Personality and Social Psychology, 2, 301-310.

Isaacson, W. (1992, August 31). The heart wants what it wants. Time, 140, $59-61$

Johnson, J. T. (1987). The heart on the sleeve and the secret self: Estimations of hidden emotion in self and acquaintances. Journal of Personality, 55, 563-582.

Johnson, J. T., Struthers, N. J., \& Bradlee, P. (1988). Social knowledge and the "secret self": The mediating effect of data base size on judgments of emotionality in the self and others. Social Cognition, 6, 319-344.

Kanouse, D. E. (1972). Language, labeling, and attribution. In E. E., Jones, D. E. Kanouse, H. H. Kelley, R. E. Nisbett, S. Valins, \& B. Weiner (Eds.), Attribution: Perceiving the causes of behavior (pp. 121-135). New York: General Learning Press.

Lowry, R. (2001, July 1). It's not personal, Mr. Bush. The Washington Post, p. B1.

Maass, A. (1999). Linguistic intergroup bias: Stereotype perpetuation through language. In M. P. Zanna (Ed.), Advances in experimental social psychology (Vol. 31, pp. 79-121). San Diego, CA: Academic Press.

Maass, A., Salvi, D., Arcuri, L., \& Semin, G. (1989). Language use in intergroup contexts: The linguistic intergroup bias. Journal of Personality and Social Psychology, 57, 981-993.

Markus, H. R., \& Kitayama, S. (1991). Culture and the self: Implications for cognition, emotion, and motivation. Psychological Review, 98, $224-$ 253.
Preacher, K. J., \& Leonardelli, G. J. (2003). [Calculation for the Sobel test] Available from http://www.unc.edu/ preacher/sobel/sobel.htm

Prentice, D. A. (1990). Familiarity and differences in self- and otherrepresentations. Journal of Personality and Social Psychology, 59, 369383.

Pronin, E., Kruger, J., Savitsky, K., \& Ross, L. (2001). You don't know me, but I know you: The illusion of asymmetric insight. Journal of Personality and Social Psychology, 81, 639-656.

Rogers, C. R. (1961). On becoming a person: A therapist's view of psychotherapy. Boston: Houghton Mifflin.

Rudolph, U., \& Forsterling, F. (1997). The psychological causality implicit in verbs: A review. Psychological Bulletin, 121, 192-218.

Ryan, R. M., \& Deci, E. L. (2003). On assimilating identities to the self: A self-determination theory perspective on internalization and integrity within cultures. In M. R. Leary \& J. P. Tangney (Eds.), The handbook of self and identity (pp. 253-272). New York: Guilford Press.

Salovey, P., Mayer, J. D., Goldman, S. L., Turvey, C., \& Palfai, T. P. (1995). Exploring emotional intelligence using the Trait Meta-Mood Scale. In J. W. Pennebaker (Ed.), Emotion, disclosure, and health (pp. 125-154). Washington, DC: American Psychological Association.

Semin, G. R., \& Fiedler, K. (1988). The cognitive functions of linguistic categories in describing persons: Social cognition and language. Journal of Personality and Social Psychology, 54, 558-568.

Semin, G. R., \& Fiedler, K. (1992). The inferential properties of interpersonal verbs. In G. R. Semin \& K. Fiedler (Eds.), Language, interaction and social cognition (pp. 58-78). Beverly Hills, CA: Sage.

Semin, G. R., \& Marsman, J. G. (1994). "Multiple inference-inviting properties" of interpersonal verbs: Event instigation, dispositional inference, and implicit causality. Journal of Personality and Social Psychology, 67, 836-849.

Semin, G. R., \& Marsman, J. G. (2000). The mnemonic functions of interpersonal verbs. Social Cognition, 18, 75-96.

Shaver, P., Schwartz, J., Kirson, D., \& O'Connor, C. (1987). Emotion knowledge: Further exploration of a prototype approach. Journal of Personality and Social Psychology, 52, 1061-1086.

Smith, E. R., \& Miller, F. D. (1983). Mediation among attribution inferences and comprehension processes: Initial findings and a general method. Journal of Personality and Social Psychology, 44, 492-505.

Sobel, M. E. (1982). Asymptotic confidence intervals for indirect effects in structural equation models. In S. Leinhardt (Ed.), Sociological methodology 1982 (pp. 290-312). Washington DC: American Sociological Association.

Suh, E. M. (2002). Culture, identity consistency, and subjective well-being Journal of Personality and Social Psychology, 83, 1378-1391.

Received October 10, 2003

Revision received June 9, 2004 Accepted June 9, 2004 